\title{
Pretraining morphine impairs acquisition and performance in the Morris water maze: Motivation reduction rather than amnesia
}

\author{
ROBERT K. MCNAMARA and RONALD W. SKELTON \\ University of Victoria, Victoria, British Columbia, Canada
}

\begin{abstract}
Two experiments were designed to assess the contribution of central opioid systems to spatial memory in the rat. In Experiment 1, rats were given morphine $(5,10$, or $20 \mathrm{mg} / \mathrm{kg}$ ), naloxone $(2 \mathrm{mg} / \mathrm{kg})$, morphine $(20 \mathrm{mg} / \mathrm{kg})$ plus naloxone $(2 \mathrm{mg} / \mathrm{kg})$, or saline and were trained to locate either a submerged or a visible platform in the Morris water maze. Pretraining, but not posttraining, morphine dose-dependently impaired acquisition and retention of the submerged platform tasks. Morphine also impaired acquisition of the visible-platform task. Naloxone reversed the morphine deficits but had no effect on place or cue learning when administered alone. In Experiment 2, rats were given morphine $(10 \mathrm{mg} / \mathrm{kg})$, naloxone $(2 \mathrm{mg} / \mathrm{kg})$, or saline and were required to locate a series of novel platform positions in either warm $\left(38^{\circ} \mathrm{C}\right.$, low incentive) or cold $\left(10^{\circ} \mathrm{C}\right.$, high incentive) water. Morphine-treated rats showed large deficits in the warm water but minimal deficits in the cold water for both the submerged and the visible platforms, suggesting that morphine impairs place and cue learning by reducing the incentive to escape.
\end{abstract}

The role of endogenous opioid systems in learning and memory processes has been the focus of increasing experimental interest, and a consistent pattern has emerged (for reviews, see Gallagher, 1984, 1985). Briefly, opioid agonists impair and opioid antagonists facilitate acquisition when administered either prior to or immediately following training. This pattern has been observed across a variety of animal memory paradigms, including heart rate conditioning (Gallagher, Kapp, McNall, \& Pascoe, 1981), avoidance conditioning (Izquierdo \& Dias, 1981; Martinez \& Rigter, 1980; Messing et al., 1979), and aversively motivated simultaneous discrimination (Castellano, 1975). The role of opioid systems in spatial memory is less clear. Rats administered naloxone after being trained on a radial maze show faster reacquisition when the maze is moved into a new environment (Gallagher, King, \& Young, 1983), yet neither naloxone nor morphine administered prior to, or immediately following, training affected performance when the radial maze was maintained in a constant environment (Beatty, 1983). The rats used in the latter study were highly overtrained, which may have reduced the sensitivity of the task to potential drug effects. More recently, it was demonstrated that naloxone administered prior to, but not immediately after, training marginally facilitated place learning in the Morris water maze (Decker, IntroiniCollison, \& McGaugh, 1989) and spatial working mem-

This research was supported by an NSERC operating grant awarded to R. W. Skelton and an NSERC PGS awarded to R. K. McNamara. The authors would like to thank Dawn McNamara for her assistance with the experiments. R. J. Sutherland is thanked for providing comments on an earlier draft of the manuscript. Correspondence should be addressed to Ronald W. Skelton, University of Victoria, Department of Psychology, P.O. Box 3050, Victoria, BC, Canada V8W 3P5. ory in the radial maze (Canli, Cook, \& Miczek, 1990). Conversely, posttraining infusion of dynorphin, an endogenous opioid peptide, into the dorsal hippocampus impaired acquisition in the Morris water maze (McDaniel, Mundy, \& Tilson, 1990). The latter two findings, which are consistent with the mnemonic pattern of impairment/ facilitation found with other paradigms, suggest that opioid activity is detrimental to spatial learning. However, McDaniel et al. (1990) also found that naloxone (3 mg/kg) alone paradoxically produced a small but significant impairment of place learning. Thus, the effects of pretraining administration of either an opioid agonist or an antagonist on place learning in the Morris water maze require further delineation.

In the present study, we sought to characterize the effects of pretraining morphine on place learning, place retention, and cue learning in the Morris water maze. Place retention and cue learning procedures were incorporated to determine whether morphine produces motivation or sensorimotor deficits that may account for its effects on place learning. The effect of posttraining morphine on place learning was also assessed. Because tolerance develops to the effects of morphine (Madden, Akil, Patrick, \& Barchas, 1977; Rosow, Miller, Poulsen-Burke, \& Cochin, 1982b; Shippenberg, Emmett-Oglesby, Ayesta, \& Herz, 1988), Experiment 1 assessed whether tolerance develops to place leaming deficits after chronic morphine treatment. Experiment 1 also examined the effects of morphine and naloxone on body temperature, since: (1) alterations of approximately $3^{\circ} \mathrm{C}$ in either direction of normothermia can produce both anterograde (Ahlers \& Riccio, 1987) and retrograde amnesia (Rauch, Welch, \& Gallego, 1989), (2) the Morris water maze requires the rat to escape from a pool of cool $\left(18^{\circ}-26^{\circ} \mathrm{C}\right)$ water (Morris, 
1981, 1984), and (3) opioid agonists and antagonists, such as morphine (Rosow, Miller, Pelkan, \& Cochin, 1980) and naloxone (Rosow et al., 1982a) influence thermoregulatory mechanisms.

\section{EXPERIMENT 1}

Method
Animals
The subjects were 55 naive hooded male rats of the Long-Evans
strain, housed in pairs in shoebox cages and maintained on a 12:12-h
light:dark cycle. Testing was conducted during the light phase of
the cycle. The rats weighed approximately $400 \mathrm{~g}$ at the beginning
of the experiment, and food and water were available ad lib.

\section{Apparatus}

The Morris water maze consisted of a circular pool (diameter, $150 \mathrm{~cm}$; height, $45 \mathrm{~cm}$ ), with a featureless white inner surface. The pool was filled to a height of $25 \mathrm{~cm}$ with $22^{\circ} \mathrm{C}\left( \pm 1^{\circ} \mathrm{C}\right)$ water, in which $1,500 \mathrm{ml}$ of powdered skim milk were dissolved. The hidden escape platform was a clear Plexiglas stand $(13 \times 13 \mathrm{~cm})$ submerged $3 \mathrm{~cm}$ below the water surface so that it was invisible at water level. The visible platform was a black stand $(13 \times 13 \mathrm{~cm})$ that protruded $5 \mathrm{~cm}$ above the surface of the water.

\section{Drugs and Group Assignment}

At the beginning of the experiment, rats were divided into nine treatment groups. The first three groups ( $n=15,5$ /group) were given pretraining injections of morphine sulfate $(5,10$, or $20 \mathrm{mg} / \mathrm{kg}$ ). The fourth group ( $n=5$ ) was treated with naloxone hydrochloride ( $2 \mathrm{mg} / \mathrm{kg}$; Sigma), the fifth group $(n=5)$ was coadministered morphine $(20 \mathrm{mg} / \mathrm{kg})$ and naloxone $(2 \mathrm{mg} / \mathrm{kg})$, the sixth group $(n=10)$ received saline $(0.9 \% \mathrm{NaCl})$, the seventh group $(n=5)$ received morphine $(20 \mathrm{mg} / \mathrm{kg}$ ) immediately after each daily training session, and the eighth group $(n=5)$ received saline posttraining. The ninth, or switch, group $(n=5)$ received saline for the first 7 days of acquisition and was switched to morphine ( $20 \mathrm{mg} / \mathrm{kg}$ ) for the remaining 7 days of training. All injections were $1 \mathrm{ml} / \mathrm{kg}$ given i.p. in the animals' home cages. Pretraining morphine and naloxone were injected 25 and $15 \mathrm{~min}$ prior to testing, respectively.

\section{Procedure}

Colonic temperature. Core body temperature was assessed colonically with an Atkins Technical Inc. thermal probe. The probe was inserted $6 \mathrm{~cm}$ into the rat's rectum for $30 \mathrm{sec}$. Colonic temperature was sampled three times daily: (1) after rats had been removed from their home cages to the holding cage (predrugnormothermia), (2) $15 \mathrm{~min}$ after injection (postdrug), and (3) after rats had swum in a pool filled with $22^{\circ} \mathrm{C}$ water for $60 \mathrm{sec}$.

Maze testing. During initial acquisition, the submerged escape platform was located in the center of the northwest quadrant. All groups were given four trials each day for 14 consecutive days. For each trial, the rat was placed in the water facing the pool wall at one of four randomly determined starting locations (north, south, east, or west pole). During each trial, the rat's swim path, drawn on a map of the pool and measured with a map-reading device, and escape latency, measured with a stopwatch to a tenth of a second, were recorded. Once the rat located the platform, it was permitted to remain on it for $10 \mathrm{sec}$. The rat was placed on the platform for $10 \mathrm{sec}$ if it did not locate the platform within $60 \mathrm{sec}$. After each trial, the rat was returned to a holding cage positioned $90 \mathrm{~cm}$ under a $250-\mathrm{W}$ brooding lamp (for warmth) and allowed to remain there for the intertrial interval (approximately $4 \mathrm{~min}$ ).

After the initial 14 days of training, a probe trial was given to assess the strength and accuracy of initial learning. Rats were re- quired to swim in the pool without the escape platform for $60 \mathrm{sec}$. All rats were released from the southern pole, and the distance traveled in each quadrant was recorded. Following this single trial, a cue task was given. Rats were required to navigate to a visible platform located in a different quadrant on each trial for four trials, and swim path lengths were recorded.

Tolerance test. Upon completion of the visible-platform task, the submerged platform was placed in the diagonally opposite $(\mathrm{NW} \rightarrow \mathrm{SE}$ ) quadrant of the pool. The saline group was divided into two $(n=5)$ groups. Half of the saline group continued to receive saline while the other half was administered morphine (10 $\mathrm{mg} / \mathrm{kg}$ ) and served as the acute group. The group that received morphine $(10 \mathrm{mg} / \mathrm{kg}$ ) throughout training continued to receive morphine during reversal training and served as the chronic group. These three groups were trained to the new platform location for 6 days (4 trials/day) and a probe trial was given on Day 7 .

\section{Data Analysis}

The differences in escape latency, swim path length, and heading error (degrees deviation from a straight line between the start position and the platform over the first $12 \mathrm{~cm}$ of the swim path) were assessed with a repeated measures analysis of variance (ANOVA). Post hoc comparisons were assessed with the use of Tukey's $(H S D)$ method and individual $t$ tests. In every case, the minimum acceptable level for statistical significance was $p<.05$.

\section{Results}

\section{Maze Testing}

Pretraining morphine produced a dose-dependent increase in swim path lengths (Figure 1A). The 10- and $20-\mathrm{mg} / \mathrm{kg}$ doses, but not the $5-\mathrm{mg} / \mathrm{kg}$ dose, increased the distance required to locate the submerged platform relative to control performance. Naloxone blocked the increased swim paths produced by the highest dose of morphine but had little effect on swim path lengths when given alone (Figure 1B). Posttraining morphine $(20 \mathrm{mg} / \mathrm{kg})$ had no effect on swim path lengths (Figure 1C). When rats were switched from saline to pretraining morphine $(20 \mathrm{mg} / \mathrm{kg}$ ) on the 8 th day of training, swim path lengths increased to levels comparable to those of rats receiving morphine from the outset of training (Figure 1C). An overall ANOVA on swim path length revealed a significant group difference $[F(3,96)=26.96, p<.001]$ and day difference $[F(13,1248)=57.13, p<.001]$, and a significant interaction between groups and day $[F(39,1248)$ $=3.15, p<.001]$. Escape latencies (data not shown) showed a similar pattern. An ANOVA of heading error (data not shown) also revealed a significant group difference $[F(3,96)=40.18, p<.001]$ and day difference $[F(13,1248)=18.89, p<.001]$, and an interaction of group and day $[F(39,1248)=1.53, p<.05]$. Post hoc analysis revealed that the 10 - and $20-\mathrm{mg} / \mathrm{kg}$ doses of morphine, but not the $5-\mathrm{mg} / \mathrm{kg}$ dose, increased swim path lengths, escape latencies, and heading errors relative to the performance of controls $(p<.01)$. The escape latencies and swim path lengths of the $20-\mathrm{mg} / \mathrm{kg}$ groups were greater than those of the $10-\mathrm{mg} / \mathrm{kg}$ group $(p<.01)$. Naloxone significantly antagonized morphine $(p<.01)$, but had no effect when administered alone $(p>.05)$. The naloxone + morphine group showed no significant differences in place learning performance (distance, latency, 


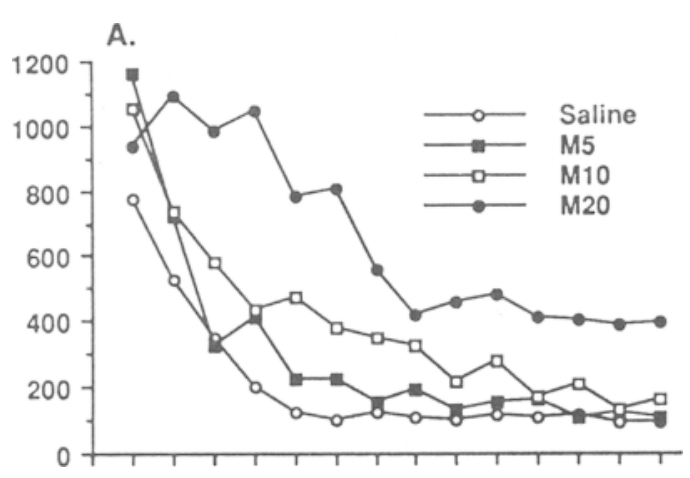

B.
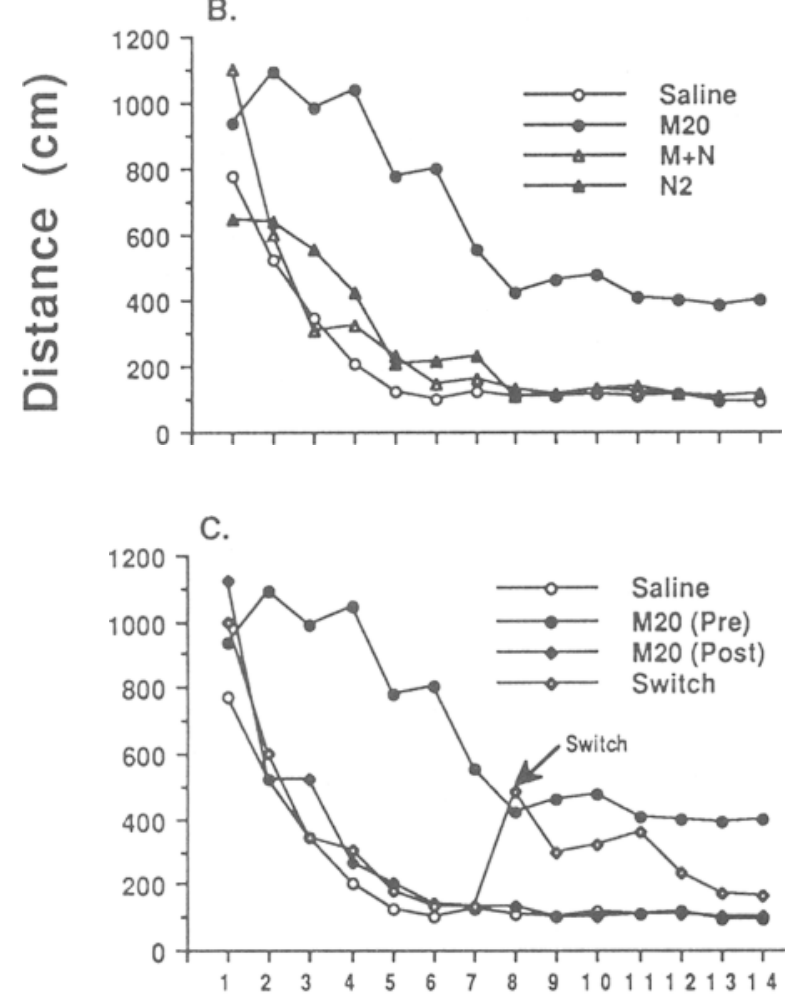

Day

Figure 1. Effects of (A) three doses of morphine, (B) naloxone and naloxone plus morphine, and (C) posttraining and postacquisition morphine on the distance taken to locate the submerged escape platform. Note: (1) the gradual improvement of morphine-treated rats, (2) the reversal of the morphine impairment by naloxone, (3) the lack of effect of posttraining morphine, and (4) the impairment of performance when rats are switched to morphine after having acquired the platform location under saline. (M = morphine; $\mathbf{N}=$ naloxone; numbers indicate dose in milligrams/kilogram of body weight.)

and heading error) relative to the control group or the naloxone group $(p>.05)$. The naloxone group did not differ from controls on any measure $(p>.05)$. Rats administered posttrial morphine did not differ from controls on any measure. The switch group did not differ from controls on any measure during the first 7 days of training but had significantly longer swim paths than controls did, once switched to morphine $(p<.01)$. During administration of pretraining morphine, the swim path lengths of the switch group did not differ significantly from those of the rats treated with morphine $(20 \mathrm{mg} / \mathrm{kg})$ from the outset.

The effects of morphine and naloxone on acquisition were confirmed in the posttraining probe trial. The distance traveled in the correct quadrant during the probe trial is shown in Figure 2. Only the rats that were administered $20-\mathrm{mg} / \mathrm{kg}$ morphine prior to daily training sessions failed to show a significant preference for the correct quadrant. Rats given 5 or $10 \mathrm{mg} / \mathrm{kg}$ morphine, posttrial morphine $(20 \mathrm{mg} / \mathrm{kg})$, morphine + naloxone, or naloxone and rats switched to morphine demonstrated an above chance (25\%) preference for the correct quadrant $(p<.01)$. Although the switch group did show a preference for the correct quadrant, this preference was significantly lower than that shown by controls $(p<.01)$.

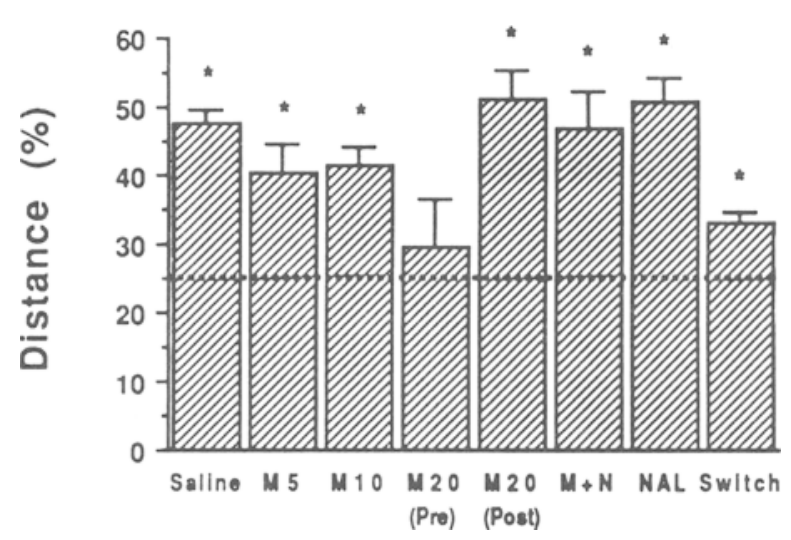

Figure 2. Effect of pretraining and posttraining morphine (M), postacquisition morphine, naloxone (NAL), and moloxone plus morphine $(M+N)$ on the distance traveled in the correct quadrant during the 60 -eec probe trial. $\quad * p<.01$ relatdve to chance level $(25 \%$; dotted line). (Error bars represent SEM.)

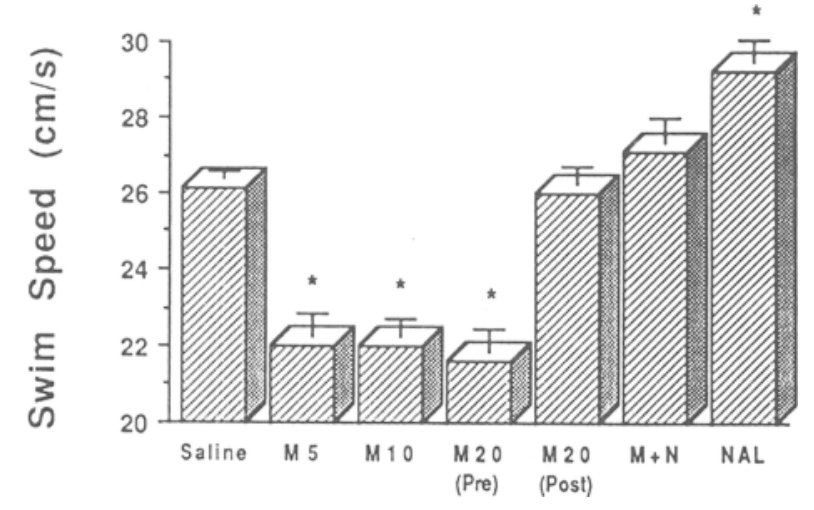

Figure 3. Effect of pretrining and posttraining morphine (M), naloxone (NAL), and naloxone plus morphine $(M+N)$ on swim speed averaged over the 14 days of testing. Note the swim speed reduction produced by the three doses of morphine and the swim speed trorease produced by naloxone. $\quad p<.01$ relative to saline performance. 


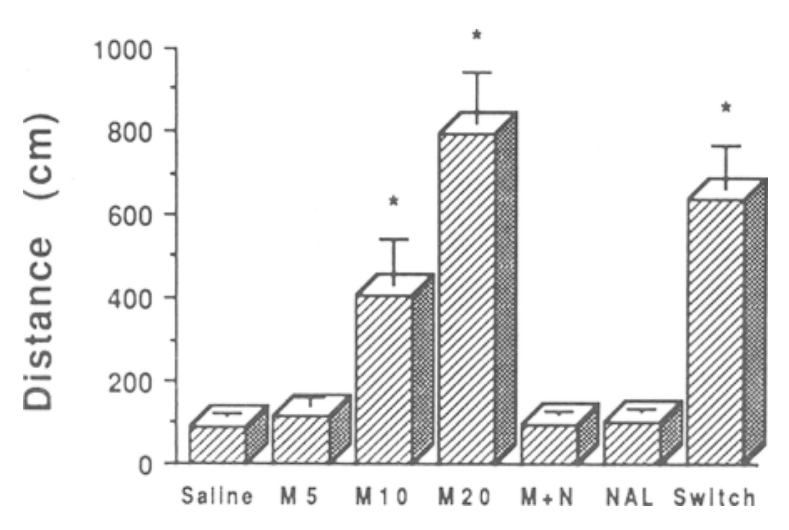

Figure 4. The distance (averaged over all trials) required by each trentment group to swim to the single visible platform. $M=$ morphine. $N A L=$ naloxone. $M+N=$ naloxone plus morphine. Note the dose-dependent impairment caused by morphine. $\quad * p<.01$ relative to saline performance.

Swim speeds were reduced by all three doses of morphine ( $p<.01$; see Figure 3); naloxone reversed this effect and also increased swim speeds when given alone $(p<.05)$. Swim speed was not reduced when morphine was administered posttraining. When rats were switched to morphine, there was a significant drop in swim speed relative to preswitch and control swim speed (preswitch, $25 \pm 0.6 \mathrm{~cm} / \mathrm{sec}$ vs. postswitch, $23 \pm 0.6 \mathrm{~cm} / \mathrm{sec} ; p<$ $.05)$. It was observed incidentally that morphine-pretreated rats, but not naloxone- or saline-treated rats, would occasionally jump off the platform after having climbed on. Further, morphine-pretreated rats displayed muscular rigidity when handled. Both of these effects were blocked by naloxone.

Unexpectedly, the $10-$ and $20-\mathrm{mg} / \mathrm{kg}$ doses of morphine impaired performance on the cue task relative to the performance of control animals ( $p<.01$; see Figure 4). Naloxone antagonized the deficit produced by the $20-\mathrm{mg} / \mathrm{kg}$ dose of morphine but had no effect when administered alone. Rats switched to morphine were also impaired when required to escape to the visible platform $(p<.05)$, although not to the same extent as rats given morphine from the outset.

\section{Tolerance Test}

The swim path distances of rats receiving morphine chronically or acutely are illustrated in Figure 5A. When the platform was reversed to the center of the opposite quadrant, rats treated chronically with morphine $(10 \mathrm{mg} / \mathrm{kg})$ showed faster acquisition relative to acutely treated rats, but they were still impaired relative to controls. There was an overall group effect $[F(3,76)=40.19, p<.001]$, and post hoc analysis revealed that the chronic morphine group had shorter swim paths than did the acute morphine $(p<.05)$, although both groups had longer swim paths than did saline-treated controls $(p<.01)$. During the probe trial (Figure 5B), only the control group showed a preference for the quadrant that had contained the submerged escape platform $(p<.01)$, suggesting that the chronic morphine rats were still impaired despite evidence of tolerance.

\section{Colonic Temperature}

Both the 10- and $20-\mathrm{mg} / \mathrm{kg}$ doses of morphine increased colonic temperature during both the postdrug and postswim phases, and this effect was antagonized by naloxone (Table 1). Naloxone had no effect on colonic temperature when given alone. An overall ANOVA revealed a significant difference between groups $[F(3,16)=4.11$, $p<.05]$ and between sampling periods $[F(1,16)=7.5$, $p<.01$ ], but no significant interaction between groups and sampling periods $[F(3,16)=0.32, p<.81]$. Post hoc comparisons revealed that the $10-$ and $20-\mathrm{mg} / \mathrm{kg}$ morphine groups demonstrated statistically significant hyperthermia during both the postdrug and postswim phases relative to saline-treated controls. The 10 - and $20-\mathrm{mg} / \mathrm{kg}$ morphine groups also demonstrated hyperthermia during the postswim phase, relative to saline-treated controls $(p<.05)$,
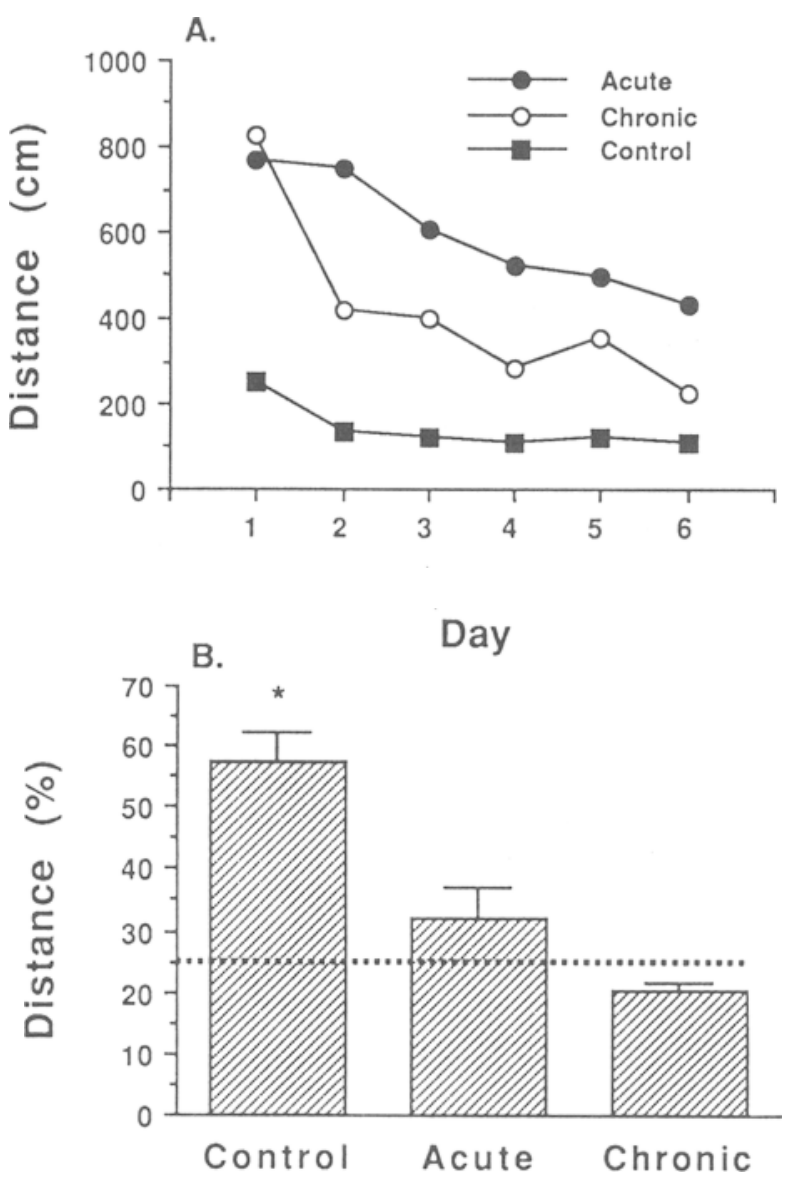

Figure 5. A comparison between rats treated chronically or acutely with morphine on (A) the distance to locate the submerged platiorm, and (B) the percent distance traveled in the correct quadrant during the probe trial. Note that rats treated chronically with morphine fail to show a preference for the correct quadrant despite improvements in acquisition. $\quad p<.01$ relative to chance level (dotted line) in panel $B$. 
Table 1

Effects of Three Different Doses of Morphine, Naloxone, and Naloxone Plus Morphine on Core Body Temperature

\begin{tabular}{|c|c|c|c|c|c|c|}
\hline \multirow[b]{2}{*}{ Group } & \multicolumn{2}{|c|}{ Predrug } & \multicolumn{2}{|c|}{ Postdrug } & \multicolumn{2}{|c|}{ Postswim } \\
\hline & $M$ & $S E M$ & $M$ & SEM & $M$ & $S E M$ \\
\hline Vehicle & 38.0 & 0.08 & 38.1 & 0.30 & 37.3 & 0.50 \\
\hline Morphine $5 \mathrm{mg} / \mathrm{kg}$ & 38.0 & 0.02 & 38.2 & 0.30 & 37.5 & 0.40 \\
\hline Morphine $10 \mathrm{mg} / \mathrm{kg}$ & 38.0 & 0.03 & 38.4 & $0.19^{*}$ & 38.1 & $0.19 *$ \\
\hline Morphine $20 \mathrm{mg} / \mathrm{kg}$ & 38.1 & 0.08 & 38.7 & $0.08 \dagger$ & 38.1 & $0.08 \dagger$ \\
\hline Naloxone & 38.1 & 0.09 & 37.9 & 0.08 & 37.4 & 0.04 \\
\hline Naloxone + Morphine $20 \mathrm{mg} / \mathrm{kg}$ & 38.1 & 0.04 & 38.1 & 0.07 & 37.4 & 0.60 \\
\hline
\end{tabular}

Note-The $20-\mathrm{mg} / \mathrm{kg}$ dose induces significant increases in core body temperature during both the postdrug and postswim phases and is reversed to control levels by naloxone. ${ }^{*} p<.05$ compared with controls. $\dagger p<.01$ compared with controls.

which showed a reduction of colonic temperature. The naloxone and naloxone + morphine groups did not differ from saline-treated controls during any sampling phase. The naloxone + morphine group did not differ significantly from the naloxone group. It should be noted that the greatest (average) deviation from normothermia was only $0.7^{\circ} \mathrm{C}$.

\section{Discussion}

In the present experiment, pretraining morphine impaired place learning in a dose-dependent manner. Medium and high doses of morphine increased the swim path lengths to the hidden platform and increased the number of days required to reach asymptotic performance. The highest dose of morphine $(20 \mathrm{mg} / \mathrm{kg})$ prevented attainment of control-level performance, increasing path lengths threefold over control levels on the last 7 days. This dose of morphine also impaired performance on the probe trial; morphine-pretreated rats failed to show a preference for the correct quadrant. The medium dose of morphine did not prevent place learning; by the end of the acquisition period, swim distances and quadrant preferences were comparable to control levels. Pretraining morphine $(20 \mathrm{mg} / \mathrm{kg})$ also impaired performance (retention). Rats given morphine $(20 \mathrm{mg} / \mathrm{kg})$ after acquiring the platform location demonstrated a deficit comparable to that for rats treated with morphine from the outset of training. Posttraining morphine $(20 \mathrm{mg} / \mathrm{kg})$ did not impair place learning.

Partial tolerance developed to morphine over the 15 days of acquisition training, but could not fully account for the control-level performance of the rats given the moderate dose of morphine. When tested with a new platform location, rats treated with the medium dose of morphine continued to be impaired, though they were not as impaired as comparably trained rats newly exposed to morphine. However, during the probe trial, neither group of morphine-treated rats demonstrated a preference for the correct quadrant, suggesting that both groups had not acquired the spatial location of the platform. Therefore, it does not appear that complete tolerance developed to the place learning deficits produced by morphine.

Morphine's effects were not limited to spatial learning. Morphine also reduced swim speeds and increased the like- lihood of jumping off the platform once the platform had been attained. Surprisingly, both the moderate and high doses of morphine impaired performance on the visibleplatform task. It should be noted that rats treated with either the moderate or the high doses of morphine were capable of climbing onto the visible platform, despite their seeming lack of desire to do so. Finally, morphine impaired the performance of a previously acquired spatial location. Together, these results suggest that morphine impairs one or several performance variables that are required for place learning, rather than place learning per se.

Naloxone antagonized all the effects of morphine, while having negligible effects when administered alone, suggesting that the effects of morphine were mediated by opioid receptors.

The failure of morphine to affect place learning when administered posttraining contrasts with the impairment of acquisition found in several studies when an opioid agonist was administered posttraining, which has often been interpreted as an interference with "consolidation" processes (see Gallagher, 1984). Our finding suggests that posttraining consolidation processes required for accurate acquisition on this task (if any) are not disrupted by increased opioid activity. This is also supported by the finding that naloxone has little effect on place learning when administered posttraining (Decker et al., 1989), although the finding that posttrial infusion of dynorphin into the dorsal hippocampus impairs place learning would argue against it. Reconciliation of this discrepancy will require further experimentation.

Morphine has many physiological actions, and it is important to consider which ones were most critical to the deficits observed, and whether these deficits represent a disruption of learning and memory or a disruption of sensory, motor, thermoregulatory, or motivational processes. Two critical findings of the present experiment consisted of the impairment by morphine of the visible-platform task and the impairment by morphine of retention in the switch group. The retention tests and the visible-platform task were employed to assess the possible contribution of nonmnemonic factors such as sensorimotor or motivational processes. The deficits of cue learning and retention observed in the present experiment suggest that morphine was not disrupting place learning specifically, but rather 
was impairing some other process necessary to learning in general. For example, morphine induces both hyperthermia (Tulunay, 1980) and muscular rigidity (Walter \& Kuschinsky, 1989), two effects that could potentially impair place learning. Although morphine did produce moderate hyperthermia in the present experiment, the magnitude of this hyperthermia $\left(0.7^{\circ} \mathrm{C}\right)$ has been demonstrated to be insufficient to impair Morris water maze performance (Rauch et al., 1989). Morphine also produced muscular rigidity, particularly at the highest dose. Despite this, however, morphine-treated rats were capable of climbing onto and of maintaining themselves on the escape platforms, and they showed no obvious disruption of swirnming. Furthermore, unlike morphine's effect on place learning, morphine's effect on swim speed was not dose dependent; the highest dose of morphine reduced swim speed to the same extent as the $5-\mathrm{mg} / \mathrm{kg}$ dose did. In addition, swim distances would not be expected to be affected by changes in swim speed. Therefore, although morphine did produce hyperthermia and muscular rigidity in the present experiment, these effects were not sufficient to account for the observed acquisition deficit.

A third non-mnemonic effect of morphine that could have interfered with learning is an impairment of visual perception (Grilly, Genovese, \& Nowak, 1980; West, Hernandez, \& Appel, 1982). An essential feature of the submerged-platform version of the Morris water maze is the utilization of ambient room cues to accurately navigate to a hidden escape platform, although other less efficient response-based strategies can be adopted (Sutherland \& Dyck, 1984). In the present experiment, morphine-treated rats were impaired even when a single local and highly visible cue (i.e., the visible platform) was available. A similar impairment was obtained in a previous study in which $10-$ and $30-\mathrm{mg} / \mathrm{kg}$, but not $5-\mathrm{mg} / \mathrm{kg}$, morphine impaired light/dark discrimination in a $\mathrm{Y}$ water maze (Castellano, 1975). Nevertheless, it is difficult to argue that rats in the present experiment were unable to locate the visible platform, because morphine-treated rats did on occasion contact the platform only to push off and continue swimming. Visual impairments were further ruled out by the observation that rats treated with a moderate dose of morphine $(10 \mathrm{mg} / \mathrm{kg})$ eventually became as proficient as controls at locating the platform and at concentrating their search in the correct quadrant during the probe trial. It might be noted that in an earlier study, rats treated with atropine methylnitrate, a peripherally acting muscarinic antagonist that causes pupillary dilation (Leopold \& Comroe, 1948), did not show place learning deficits in the Morris water maze (Sutherland, Whishaw, \& Regehr, 1982). Therefore, it seems unlikely that visual/perceptual deficits alone could account for the observed learning deficit.

A final non-mnemonic effect of morphine that may have produced the observed learning impairments is analgesia/ antinociception (Lloyd, Appel, \& McGowan, 1978; Martin,
1984; Rochat, Cervo, Romandini, \& Samanin, 1982). In the present experiment, morphine could have attenuated the aversiveness of the cold water, thereby reducing the rat's incentive to escape. Three observations from the present experiment indicate that morphine-treated rats did not find the cold water as aversive as controls did: Morphine-treated rats swam slower, took longer to initiate swimming when placed into the water, and were more likely to jump off the platform than were controls. All of these effects resemble the consequences of reducing the incentive value of water by making it warmer (Wever, 1932). In Experiment 2, this interpretation of the morphine-induced deficits was investigated.

\section{EXPERIMENT 2}

In Experiment 1, morphine-treated rats demonstrated several behaviors that suggested that the perceived aversiveness of the cold water was diminished. Indeed, the behavior of morphine-treated rats resembled that displayed by rats trained to escape from warmer water. For example, Wever (1932) noted that at warmer water temperatures, rats "did not head for the goal immediately, but spent some time in casual exploration, or for a few moments remained motionless at the entrance ... and then finally at a relatively slow and leisurely gait swam to the landing platform"' (p. 222). Therefore, it seems possible that the poorer performance of morphine-treated rats was due not to interruptions of memory processes, but rather to a decrease in motivation due to an attenuation of the aversiveness of the $22^{\circ} \mathrm{C}$ water. Experiment 2 assessed whether increased incentive to escape (cold water) could reverse the place and cue deficits produced by morphine.

\section{Method}

\section{Animals and Apparatus}

Eighteen naive hooded male rats of the Long-Evans strain served as subjects. The rats were maintained as described in Experiment 1, and the same Morris water maze was used.

\section{Drugs and Group Assignment}

The rats were divided into one of three treatment groups receiving morphine sulfate $(n=6 ; 10 \mathrm{mg} / \mathrm{kg})$, naloxone hydrochloride $(n=6 ; 2 \mathrm{mg} / \mathrm{kg}$ ), or saline $(n=6,1 \mathrm{ml} / \mathrm{kg}$ ). All drugs were dissolved in saline $(0.9 \% \mathrm{NaCl})$ and administered i.p. in the rat's home cage $\mathbf{2 0}$ min prior to behavioral testing. All rats in each group were tested in both conditions (cold water and warm water).

\section{Procedure}

The maze training was a modification of the "moving platform" task described by Whishaw (1985); the rats were required to learn a new platform location on each test day (eight trials/day). The procedure differed from Whishaw's (1985), in that each trial was separated by an interval of approximately $4 \mathrm{~min}$. Water temperature alternated between $38^{\circ} \pm 1^{\circ} \mathrm{C}$ and $10^{\circ} \pm 1^{\circ} \mathrm{C}$ on successive days. Each rat was tested six times in both water temperatures (one temperature/day), with a new platform position each time. In addition to latency and distance measures, the incidence of jumping off the platform was also recorded. On the 6th and final day of each incentive condition, the platform was removed after the eighth trial and each rat was given a $60-\mathrm{sec}$ probe trial. During the final 2 days 
A.

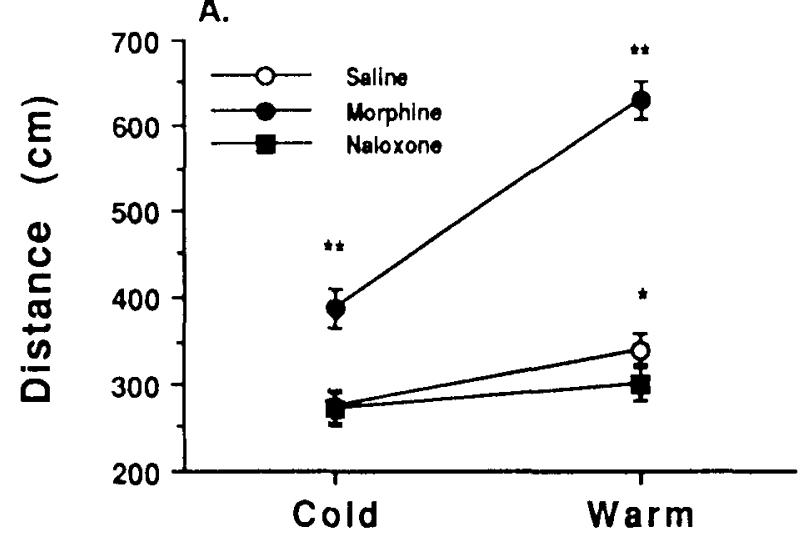

B.

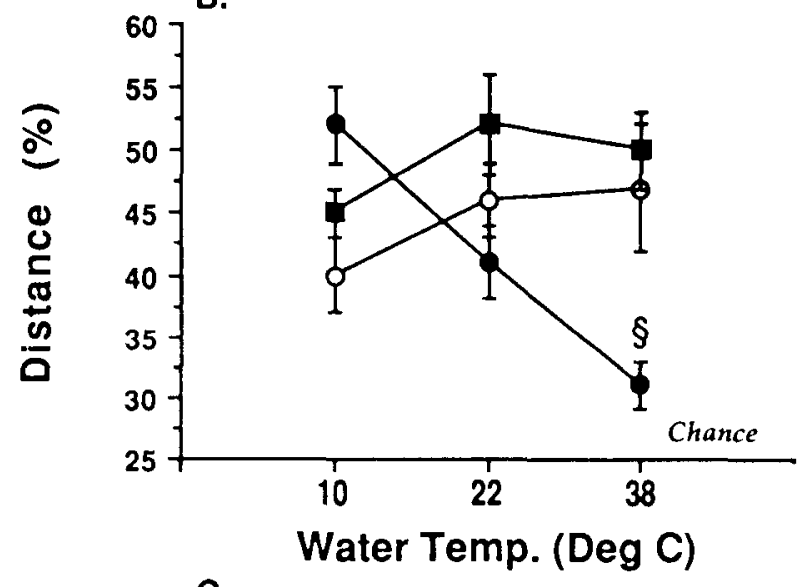

C.

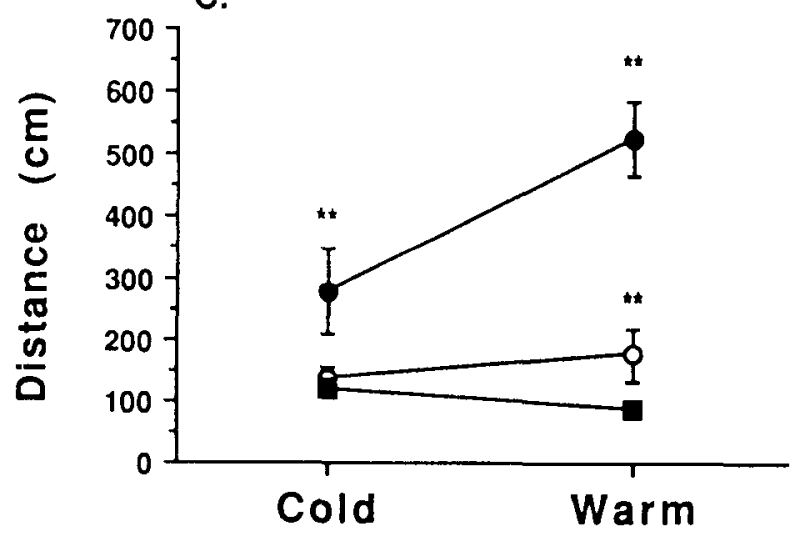

Figure 6. Effects of morphine and maloxone on $(A)$ the distance taken to locate the submerged platform in elther cold $\left(10^{\circ} \pm 1^{\circ} \mathrm{C}\right)$ or warm $\left(38^{\circ} \pm 1^{\circ} \mathrm{C}\right.$ ) water (averaged over all trinls under each condition) and (B) the distance traveled in the correct quadrant during cold- and warm-water probe trials as well as performance on the Experiment 1 probe trial $\left(22^{\circ} \pm 1^{\circ} \mathrm{C}\right)$. (C) The distance taken to navigate to the vistble platform (averaged over all trials in each condition). $\quad *<.05$ compared with noloxone performance as well as cold-water performance. $\quad * p<.01$ compared with control levels. $\zeta p>.05$ compared with chance level $(25 \%)$ in panel B; all other means are significantly greater than chance levels $(25 \%)$. of testing, colonic temperatures were sampled at six phases during testing to determine whether hyper- or hypothermia resulted from the drug and/or water temperature. When the moving platform task was completed, rats were tested with the visible platform (as described in Experiment 1) under both incentive conditions.

\section{Results}

Water temperature affected place learning in both salineand morphine-treated rats. In warm water, morphinetreated rats demonstrated a marked impairment relative to saline- or naloxone-treated rats $(p<.01)$. In cold water, morphine-treated rats performed nearly as well as controls, although they did differ from controls significantly $(p<.01$; see Figure $6 \mathrm{~A})$. In cold water, salinetreated rats were better able to find the submerged platform, with distances significantly shorter than in the warm-water condition $(p<.05)$. Naloxone-treated rats were significantly faster than controls in warm water $(p<.05)$ and did not show a significant improvement between cold- and warm-water conditions.

None of the rats from any treatment group jumped off the platform when the water was cold. However, when the water was warm, the morphine-treated rats frequently jumped off the platform (probability $=0.42 \pm 0.06$ ), unlike the controls, who jumped off infrequently $(0.03 \pm$ 0.03 ), and the naloxone-treated rats, who did not jump off at all.

In the probe trials, morphine-treated rats did not show a preference for the correct quadrant when the water was warm, yet they showed a clear preference $(p<.01)$ when the water was cold (Figure 6B). Saline- and naloxonetreated rats showed a clear preference for the correct quadrant under both temperatures, with naloxone-treated rats tending to show a greater preference relative to controls $(p>.05)$. The probe data from Experiments 1 and 2 are plotted together in Figure 6B, which shows that water temperature had a systematic effect only on morphinetreated rats. For these rats, the diligence of the search in the correct quadrant was directly related to the temperature of the water.

Morphine-treated rats showed exactly the same pattern of impairments in the visible-platform task as they had during the submerged-platform task (Figure 6C). During the cold-water condition, morphine-treated rats showed only a slight impairment relative to saline- and naloxonetreated rats $(p<.01)$, but they showed a large impairment during the warm-water condition relative to both controls and cold-water performance $(p<.01)$. Salinetreated rats showed similar performance during both coldand warm-water conditions. Naloxone-treated rats actually performed better in warm water than in cold, although this effect failed to reach statistical significance, and they were significantly better than controls in warm water $(p<.05)$. Swim speeds were lower for all groups in the warm-water condition $(p<.01)$ in both the visible- and the submerged-platform tasks (data not shown). 

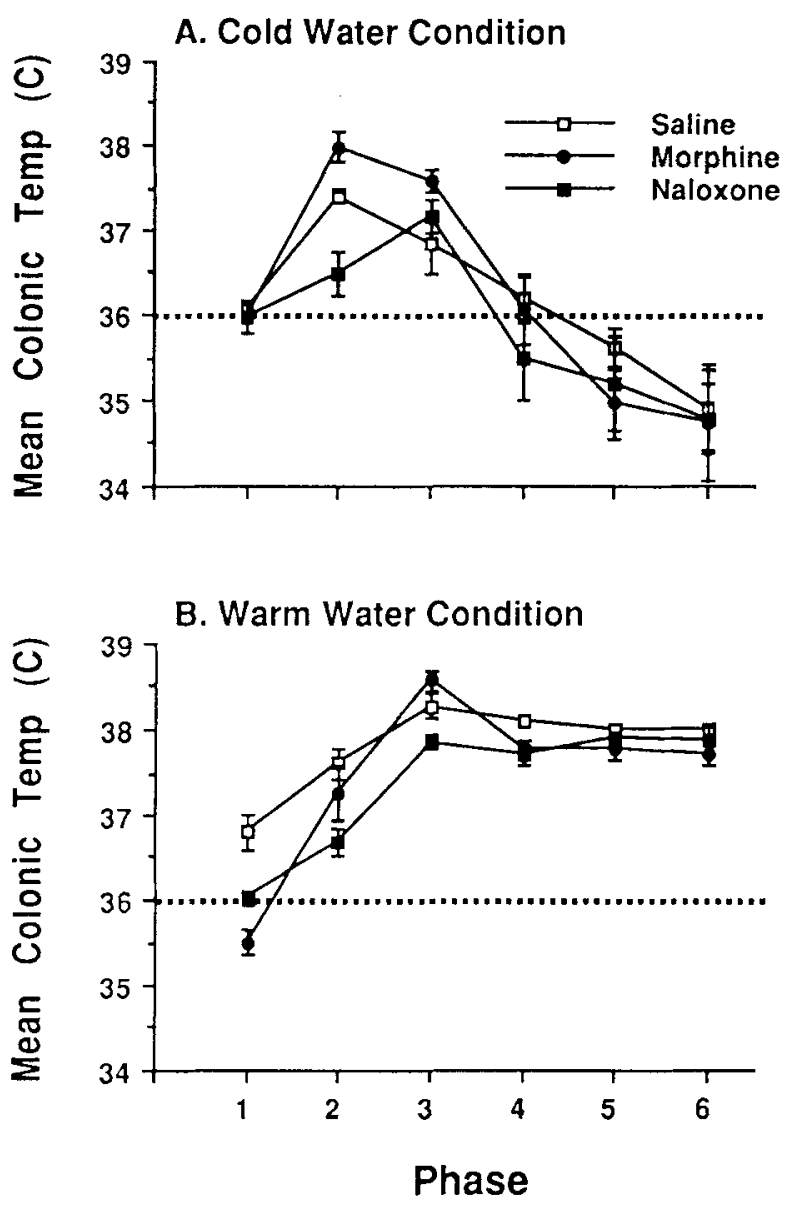

Figure 7. Effects of morphine and naloxone on core body temperature sampled before testing (Phase 1), $20 \mathrm{~min}$ after drug administration (Phase 2), and at four points (after every second trial) during testing in the water maze in either (A) cold or (B) warm water. (Dotted line represents mean for three treatment groups on Phase 1.)

Morphine produced significant hyperthermia between Phase 1 and Phase 2 in both cold- and warm-water conditions $(p<.01)$, producing a $2^{\circ} \mathrm{C}$ increase in core body temperature in the warm-water condition (Figure 7). Saline and naloxone also increased core body temperature, although these increases failed to reach statistical significance relative to baseline levels. Overall, colonic temperatures declined in cold water and rose in warm water. The mean colonic temperature for each group under each water temperature did not increase or decrease more than $2^{\circ} \mathrm{C}$. An overall ANOVA failed to reveal significant differences between groups $(p>.05)$, though there were significant $(p<.05)$ changes between sampling periods.

\section{Discussion}

The main finding of this experiment is that the learning deficit produced by morphine in warm water can be largely overcome by lowering the water temperature used to motivate escape. In the warm-water condition, morphinetreated rats demonstrated an acquisition impairment rela- tive to their cold-water performance, were more likely to jump off the platform than controls, and failed to show a preference for the correct quadrant during the probe trial. When the water was cold, morphine-treated rats demonstrated only a marginal deficit relative to controls during acquisition, showed a greater preference than controls for the correct quadrant during the probe trial, and did not jump off the platform. Further, saline-treated rats performed better in cold water, suggesting that the cold water was sufficient to increase escape motivation. The latter result is consistent with the finding of Selden, Cole, Everitt, and Robbins (1990) that rats trained in cold water $\left(12^{\circ} \mathrm{C}\right)$ showed a stronger spatial bias for the correct quadrant during the probe trial than did rats trained in warm water $\left(26^{\circ} \mathrm{C}\right)$. Interestingly, in the present study, naloxone-treated rats performed optimally in both warm and cold water, suggesting the rather paradoxical conclusion that the warm water elicited endogenous opioid activity that was detrimental to performance. If present, this endogenous opioid activity may have exacerbated the morphine deficit. It is possible, then, that cold water does not elicit the same degree of endogenous opioid activity as warm water does, thereby attenuating the morphine deficit. However, this conclusion contrasts with previous reports that cold water elicits cold endogenous opioid activity (Barta \& Yashpal, 1981). An alternative interpretation is that the cold water may have elicited the release of hormones (e.g., epinephrine) that facilitated the performance of morphine-treated rats. The place learning deficits produced by morphine in the warm-water condition are unlikely to be due to drug-induced alteration of body temperature, since the magnitude of this change was below that found to affect mnemonic processes (Ahlers \& Riccio, 1987). These data, along with the data from Experiment 1, suggest that morphine-treated rats can learn the location of a place, or swim to a single visual cue, when the incentive to escape is increased to overcome the antinociceptive effects of the drug.

\section{GENERAL DISCUSSION}

Experiment 1 demonstrated that morphine impairs place learning, place recall, and cue learning; it lengthened swim paths and increased heading errors. The place and cue learning deficits were mediated via endogenous opioid receptors since they were reversed by naloxone. Rats treated with a moderate dose of morphine $(10 \mathrm{mg} / \mathrm{kg})$ showed a gradual improvement in performance over training and developed a preference for the correct quadrant. However, this improvement was not due to the development of tolerance, since the same rats were impaired at learning the reversed platform position. Experiment 2 demonstrated that morphine-treated rats can acquire spatial relationships with an efficiency comparable to that of controls if the incentive value of escape is increased. Morphine-treated rats showed large deficits in warm water but minimal deficits in cold water. These findings suggest that in the Morris water maze, morphine does not impair spatial learning 
per se, but rather impairs the motivation to learn. This effect is consistent with morphine's characteristic analgesic/ antinociception actions (Martin, 1984).

The finding that the preadministration of an opioid agonist impairs acquisition contrasts with the findings of Beatty (1983), who found that the preadministration of comparable doses of morphine did not impair spatial working memory on an appetitively motivated eight-arm radial maze. Perhaps the difference between the present findings and those of Beatty is related to the difference between appetitively and aversively motivated tasks. Interestingly, both naloxone and morphine suppress food intake in the rat (e.g. , Frenk \& Rogers, 1979), suggesting that naloxone- and morphine-treated rats would also lose their incentive to acquire the radial maze. Surprising, then, is the finding that naloxone enhances spatial working memory in this task (Canli et al., 1990).

Naloxone has been shown to enhance learning and memory processes across a wide variety of tasks (Gallagher, 1984), suggesting that endogenous opioid activity can disrupt optimal learning. Recently, Decker et al. (1989) demonstrated that the pretraining administration of naloxone enhanced acquisition in the Morris water maze. However, in the present study, naloxone had little or no effect on acquisition. This discrepancy may be accounted for by the different number of trials given each day. For example, the two-trial-per-day procedure employed by Decker et al. would be more difficult for control rats, taking longer to reach asymptotic levels, thereby allowing for an enhancement to be revealed. Furthermore, the use of different rat strains and/or drug doses may also account for the discrepancy. However, the $3-\mathrm{mg} / \mathrm{kg}$ dose of naloxone that Decker et al. found to enhance acquisition has also been shown to impair acquisition in the Morris water maze using the same procedures as those of the present study (McDaniel et al., 1990). Thus, the role of endogenous opioid systems in place learning requires further clarification.

In sum, it was demonstrated that morphine impaired both place and cue learning via opioid receptors, in a dosedependent manner. This impairment could not be attributed to drug-or environmentally induced alterations in body temperature, or to motor or perceptual deficits. However, the results of Experiment 2 suggested that morphine impaired place and cue learning by reducing the incentive to escape, rather than by interfering with memory processes per se. It is our interpretation that morphine's antinociceptive/analgesic action reduced the aversive nature of the water, thereby reducing the motivation to escape from it. Finally, naloxone had little effect on either place or cue learning. These results suggest that endogenous opioid systems have a negligible role in place learning, and they emphasize that one should be cautious when interpreting experiments in which the preadministration of morphine seems to disrupt aversively motivated learning.

\section{REFERENCES}

AHLERs, S. T., \& Riccio, D. C. (1987). Anterograde amnesia induced by hyperthermia in rats. Behavioral Neuroscience, 101, 333-340.

Barta, A., Yashpal, K. (1981). Regional redistribution of $\beta$ endorphin in the rat brain: The effect of stress. Progress in NeuroPsychopharmacology, 5, 595-598.

BeAtTY, W. W. (1983). Opiate antagonists, morphine and spatial memory in rats. Pharmacology, Biochemistry \& Behavior, 19, $397-401$.

CANLI, T., CoOK, R. G., MICZEK, K. A. (1990). Opiate antagonists enhance the working memory of rats in the radial maze. Pharmacology, Biochemistry \& Behavior, 36, 521-525.

Castellano, C. (1975). Effects of morphine and heroin on discrimination learning and consolidation in mice. Psychopharmacology, 42, 235-242.

Decker, M. W., Introini-Collison, I. B., MCGaugh, J. L. (1989). Effects of naloxone on Morris water maze learning in the rat: Enhanced acquisition with pretraining but not posttraining administration. Psychobiology, 17, 270-275.

Frenk, H., Rogers, G. H. (1979). The suppressant effects of naloxone on food and water intake in the rat. Behavioral \& Neural Biology, 26, 23-40.

Gallagher, M. (1984). Neurochemical modulation of memory: A case for opioid peptides. In L. R. Squire \& N. Butters (Eds.), Neuropsychology of memory (pp. 579-587). New York: Guilford.

Gallagher, M. (1985). Reviewing modulation of learning and memory. In N. M. Weinberger, J. L. McGaugh, \& G. Lynch (Eds.), Memory systems of the brain: Animal and hwman cognitive processes (pp. 311334). New York: Guilford.

Gallagher, M., Kapp, B. S., McNall, C. L., \& Pascoe, J. P. (1981). Opiate effects in the amygdala central nucleus on heart rate conditioning in rabbits. Pharmacology, Biochemistry Behavior, 14, 497-505.

Gallagher, M., KING, R. A., \& Young, N. B. (1983). Opiate antagonists improve memory. Science, 221, 975-976.

Grilly, D. M., Genovese, R. F., \& Nowak, M. J. (1980). Effects of morphine, d-amphetamine, and pentobarbital on shock and light discrimination performance in rats. Psychopharmacology, 70, 213-217.

IzQuiERDo, I., DIAS, R. D. (1981). Retrograde amnesia caused by Met-, Leu- and dis-Try-Met-enkephalin in the rat and its reversal by naloxone. Neuroscience Letters, 22, 189-193.

LeOPOLD, I. H., \& COMROE, J. H. (1943). Effect of intramuscular administration of morphine, atropine, scopolamine and neostigmine on the human eye. Archives d'Opthalmologie, 46, 285-290.

Lloyd, M. A., APPEL, J. B., a McGowan, W. T. (1978). Effects of morphine and chlorpromazine on the detection of shock. Psychopharmacology, 58, 241-246.

Madden, J., AkIl, H., Patrick, R. L., * Barchas, J. D. (1977). Stress-induced parallel changes in central opioid levels and pain responsiveness in the rat. Nature, 265, 358-360.

Martin, W. R. (1984). Pharmacology of opioids. Pharmacological Reviews, 35, 283-323.

MARtinez, J. L., R Rugter, H. (1980). Endorphins alter acquisition and consolidation of an inhibitory avoidance response in rats. Neuroscience Letters, 19, 197-201.

McDaniel, K. L., Mundy, W. R., Tilson, H. A. (1990). Microinjection of dynorphin into the hippocampus impairs spatial learning in rats. Pharmacology, Biochemistry \& Behavior, 35, 429-435.

Messing, R. B., Jensen, R. A., Martinez, J. L., Spiehler, V. R., VAsquez, B. J., SOUMmeU-Mourat, B., LIANG, K. C., \& MCGAugh, J. L. (1979). Naloxone enhancement of memory. Behavioral \& $\mathrm{Neu}$ ral Biology, 27, 266-275.

Morris, R. G. M. (1981). Spatial localization does not require the presence of local cues. Learning \& Motivation, 12, 239-260.

MorRIs, R. G. M. (1984). Developments of a water-maze procedure for studying spatial learning in the rat. Journal of Neuroscience Methods, 11, 47-60.

Rauch, T. M., Welch, D. I. , Gallego, L. (1989). Hyperthermia 
impairs retrieval of an overtrained spatial task in the Morris water maze. Behavioral \& Neural Biology, 52, 321-330.

Rochat, C., Cervo, S., Romandini, S., \& Samanin, R. (1982). Differences in the effects of $d$-fenfluramine and morphine on various responses of rats to painful stimuli. Psychopharmacology, 76, 188-192.

Rosow, C. E., Miller, J. M., Pelkan, E. W., Cochin, J. (1980). Opiates and thermoregulation in mice: I. Agonists. Joumal of Pharmacology \& Experimental Therapeutics, 213, 273-283.

Rosow, C. E., Miller, J. M., Poulsen-Burke, J., * Cochin, J. (1982a). Opiates and thermoregulation in mice: II. Effects of opiate antagonists. Journal of Pharmacology \& Experimental Therapeutics, 220, 464-467.

Rosow, C. E., Miller, J. M., Poulsen-Burke, J., * Cochin, J. (1982b). Opiates and thermoregulation in mice: IV. Tolerance and cross-tolerance. Joumal of Pharmacology \& Experimental Therapeutics, 233, 702-708.

Selden, N. R. W., Cole, B. J., Everitt, B. J., \& Robiins, T. W. (1990). Damage to ceruleo-cortical noradrenergic projections impairs locally cued but enhances spatially cued water maze acquisition. $B e-$ havioural Brain Research, 39, 29-51.

Shippenberg, T. S., Emmett-OGlesby, M. W., Ayesta, F. J., \& Herz, A. (1988). Tolerance and selective cross-tolerance to the motivational effects of opioids. Psychopharmacology, 96, 110-115. SUTherland, R. J., \& DYCK, R. H. (1984). Place navigation by rats in a swimming pool. Canadian Journal of Psychology, 38, 322-347.
Sutherland, R. J., Whishaw, I. Q., \& Regehr, J. C. (1982). Cholinergic receptor blockade impairs spatial localization by use of distal cues in the rat. Journal of Comparative \& Physiological Psychology, 96, 563-573.

TULUNAY, F. C. (1980). The effects of morphine and various narcotic antagonist type analgesics on body temperature in rats. Life Sciences, 27, 511-520.

WALTER, S., KuschinsKy, K. (1989). Conditioning of morphineinduced locomotion activity and stereotyped behaviour in rats. Journal of Neural Transmission, 78, 231-247.

West, K. B., Hernandez, L. L., A APPel, J. B. (1982). Drugs and visual perception: Effects of LSD, morphine and chlorpromazine on accuracy, bias and speed. Psychopharmacology, 76, 320-324.

WEVER, E. G. (1932). Water temperature as an incentive to swimming activity in the rat. Joumal of Comparative \& Physiological Psychology, 14, 219-224.

Whishaw, I. Q. (1985). Formation of a place learning-set by the rat: A new paradigm for neurobehavioral studies. Physiology \& Behavior, 35, 139-143.

(Manuscript received March 25, 1991; revision accepted for publication July 1, 1991.) 